\title{
THE FEMALE OF CNODOCENTRON (CAENOCENTRON) YAVAPAI MOULTON AND STEWART (TRICHOPTERA: XIPHOCENTRONIDAE)
}

\author{
David E. Ruiter ${ }^{1}$
}

Key words: Xiphocentronidae, Arizona, description.

During examination of Arizona caddis collections, I discovered a male Cnodocentron yavapai Moulton and Stewart. It had been collected about $1.5 \mathrm{~km}$ south of the Bubbling Springs, Yavapai County, Arizona, type locality. A female, indistinguishable from the male in overall nongenitalic characters, was present in the same collection. This female is figured and described, designated as the C. yavapai allotype female, and deposited at the National Museum of Natural History, where the holotype is located.

\section{Cnodocentron yavapai \\ Moulton and Stewart 1997}

(Fig. 1A-D)

Adult female.-Head, thorax, abdomen brown (in alcohol); spurs 2-4-4 and hairy; wings with numerous fine surface setae and long posterior setal fringes. Apical maxillary palp segment flexible, longer than previous 4 segments combined. Eighth abdominal segment tubular, dorsal surface membranous dorsomesally. Ninth abdominal segment retractile within 8th segment, ventroapical portion with faint sclerotized structures.

COLlECTION DATA.-Arizona: Yavapai County, Oak Creek, Page Springs Road at town of Page Springs; swept from streamside bushes, 3 June 2003, B.C. Kondratieff and J. Schmidt.

I thank Boris Kondratieff and Jason Schmidt for the opportunity to examine their material.

\section{Literature Cited}

Moulton, S.R., II, And K.W. Stewart. 1997. A new species and first record of the caddisfly genus Cnodocentron Schmid (Trichoptera: Xiphocentronidae) north of Mexico. Pages 343-347 in R.W. Holzenthal and O.S. Flint, Jr., editors, Proceedings of the 8th International Symposium on Trichoptera. Ohio Biological Survey. 


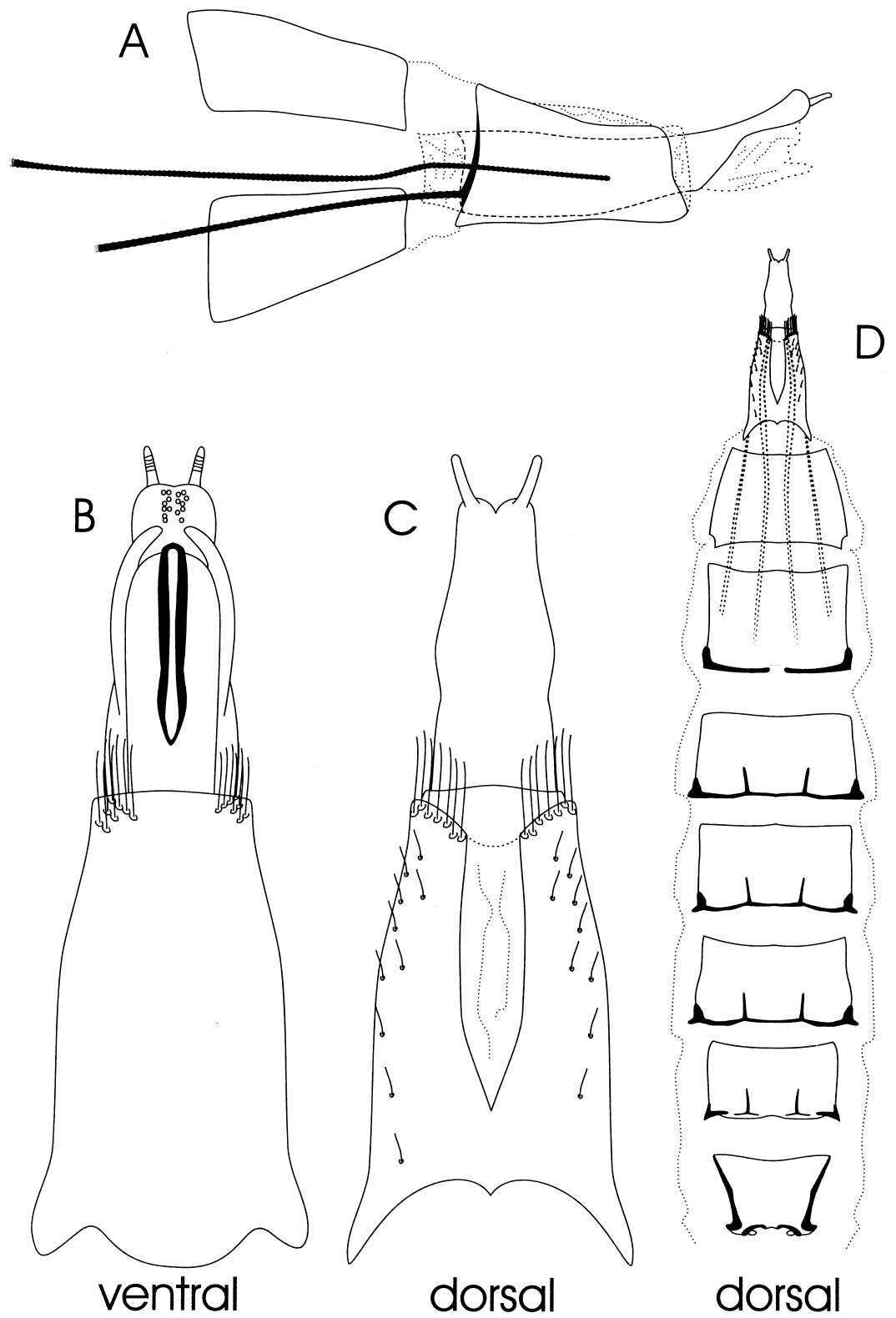

Fig. 1. Cnodocentron yavapai female: (A) apical abdominal segments, left lateral view; (B) 8th-10th abdominal segments, ventral view; (C) 8th-10th abdominal segments, dorsal view; (D) abdomen, dorsal view. 